\title{
Parametric Study of Filter Lengths Effect on Stability of Earth Dams
}

\author{
Thamir Mohammed Ahmed ${ }^{1}$
}

\author{
${ }^{1}$ Civil Engineering Department, Tishk International University, Erbil, Iraq \\ Correspondence: Thamir Mohammed Ahmed, Tishk International University, Erbil, Iraq. \\ Email: thamir.ahmed@tiu.edu.iq
}

\section{Doi: 10.23918/eajse.v6i1p56}

\begin{abstract}
Seepage is one of the main reasons behind the earth's dam failure which needs high attention to prevent or govern its negative effect. One of the most effective parts that may reduce the effect of seepage and keep it within permissible limits is the filter which mostly installed at the downstream end of the dam base. In this study, the effect of many filter lengths on the main stability elements of the earth dam due to downstream arc failure was examined. Furthermore, the filter length effect on the seepage amount and behavior of pore water pressure has also been studied. Different random homogenous silty earth dam sections have been used and the analyses using the (SLOPE/W and SEEP/W) numerical analysis program were performed. The findings showed that filter length has a significant effect on the variation of pore water pressure whereas less effect is indicated on the rate of seepage flow inside the earth dam body.
\end{abstract}

\section{Keywords: Earth Dam Filter, Earth Dam Stability, SEEP/W}

\section{Introduction}

Earth dams are considered vital and strategic hydraulic structures that are directly related to the water and economic security of countries. The importance of this type of structure attributed to providing water and energy needs. The design and implementation of these structures as well as their operation have received the attention of many companies and researchers due to their wide range of functions such as storage control, demand requirements, and electrical power energy generation as well as their low cost compared to other types of dams.

Earth dams are less rigid and hence more susceptible to failure. Every past failure of such a dam has contributed to an increase in the knowledge of the earth dam designers. Earthen dams may fail, like other engineering structures, due to improper designs, faulty constructions, lack of maintenance, etc. The various causes leading to the failure of earth dams can be grouped into the following three classes: (1) Hydraulic failures, (2) Seepage failures, and (3) Structural failures.

Analysis of seepage and its influencing factors on the stability of earth dams is considered this work. Controlled seepage or limited uniform seepage is inevitable in all earth dams, and usually, it does not produce any harm. However, uncontrolled or concentrated seepage through the dam body or its foundation may lead to piping or sloughing and the subsequent failure of the dam (Tatewar \& Pawade, 2012).

\section{Previous Studies}

The method of the finite element was used to apply for a seepage problem solution which was known as (back analyses) parameter estimation. The model that was experimented with was FUKADA earth dam. It was assumed to be a two-dimensional flow, one of the plane, anisotropic, isoperimetric, and quadratic element. An error procedure and a trial were used to analyze the permeability through the saturated and unsaturated zone. A series of repeated calculations were carried out to solve this problem by taking various possible parameters. Finally, a negligible difference was obtained by initially finding the difference between the measured and calculated seepage lines (Chowhury et al., 1996). 
A case study provides an outline of the technology and methods used for determining scour potential during a dam overtopping event was made by (George \& Annandale, 2006). For the scenario at Smith Mountain Dam, the EIM, CFM, and DI models were used to show that no significant scour of the rock on the abutments or thrust blocks was to occur during the PMF. Should there be a potential for scouring by dynamic impulsion, a methodology was developed to aid in the design of rock anchoring that could be generically applied to a variety of scenarios and not just Smith Mountain Dam. A concrete cut-off wall is widely used in the reinforcement project of the earth rockfill dam. To analyze the influence of cut-off wall on dam slope stability, a finite element numerical model coupling both the seepage and stress field was developed by (Fei \& Zhang, 2010), to enable the calculation of factor of safety of dam slope stability and to compare the differences before and after the reinforcement using strength reduction finite element method. Research shows that under normal storage conditions, the safety factor of downstream dam slope increases significantly after building a cut-off wall while it reduces slightly for the upstream dam slope. Based on the analysis of the impact of the cut-off wall on the seepage and stress field of the dam, this paper used a strength reduction finite element method to assess the stability of both upstream and downstream dam slope before and after building cut-off wall.

The effect of drawdown conditions on the stability of the earth dam has been studied by (Al-Labban, 2018). The drawdown considered as the main factor causing the increase in seepage force which in turn moved the soil particles in the same direction of flow and cause erosion problems. In the study exit gradients and slope stability under both steady-state and transient conditions were analyzed using the finite element method (FEM). The study concluded that the construction of core combined with cutoff is essential in reducing the seepage flow through the dam body. Furthermore, it is found that as a result of the drawdown condition, a higher water flux to flow out of the dam is observed. Thus the installation of an upstream filter may control this problem and reduce the probability of upstream failures.

The finite element method with the SEEP / W program was used by (Abbas, 2017) to determine the amount of flow through homogeneous dikes with a triangular toe filter. Effects of slope angle, foot filter angle, dam height, top dam width, freeboard, toe length filter, and permeability coefficient on the quantity of seepage flux were studied. The results showed that the amount of leakage decreased with increasing the filter inclination, freeboard height, and top width of the dam. The study also reported that the amount of flux increased with increasing angle of upstream and downstream slopes, and the length of the toe filter. An experimental equation has been proposed by using statistical analysis by SPSS-19 to estimate the amount of leakages within the dams with triangular toe filter.

Many scenarios have been applied by (Luca \& Pop, 2016) to evaluate the performance of the Iasi earth dam in Romania under operation. The evaluation criteria included studying the filtration phenomenons using Darcy's Law and Post-Darcy Law, in addition to monitoring the stability considered the main operating situations. The filtration and embankment behavior simulation were analyzed using a specialized soft. The studies concluded that monitoring is essential in evaluating the structural safety condition of dams and useful for the collection of valuable data to enhance the understanding of the behavior of these structures.

The stability analysis of an earth dam using the GEO-SLOPE model under different soil conditions has been conducted by (Mishal \& Khayyun, 2018). An equation based on the soil geometrical parameters such as weight density. The angle of repose, cohesive strength, water depth seepage flux, and permeability coefficient was derived. The equation is verified by using many parameters that 
control the safety factor of the earth dam which were simulated by using the finite element model. The model used all dimensions and features of the Al-Adhaim dam as a case study to drive an empirical equation that could be used for safety other regarding equations and it is found that the results are close to each other.

A parametric study using finite elements of analyzing the stability of the slope is presented in this work. Comparison with other methods of the solution is also performed, including the effect of the free surface on the slope stability and dam stability (Griffiths \& Lane, 1999). The graphic output is included to illustrate distortions and failure mechanisms. The finite element method of slope stability analysis is said to be a more robust alternative to conventional equilibrium methods and its widespread use should now be standard in geotechnical practice.

In this study, several earthen dam sections were designed and analyzed by adopting the most used storage levels using the geo-studio program and comparing the results with those obtained by the traditional calculation method.

\section{Methodology}

In the current study, a geo studio program was used to analyze the D/S slope stability of the earthen dam, as well as the behavior of flow lines within the dam body, by adopting the homogeneous and isotropic soil hypothesis. The study has also included studying the effect of different lengths of the horizontal filter on the stability of the dam. First, a steady-state analysis (SEEP/W) is used to compute the total head, the exit gradient, and the seepage magnitude through the earth dam. This step is necessary to determine the magnitude and the direction of the water flow through the earth dam. Besides, the SLOPE/W stability analysis has been used to examine the D/S slope stability based on the critical arc of failure. The application of the program has been focused on studying the effect of filter length on pore water pressure, normal forces, and shear forces resulting from slope stability analysis, as well as the pore water pressure resulting from the amount of seepage flow entering the dam body.

\section{Slope Stability Analysis}

The following figures show the behavior of the exudation line in the case of using different lengths of filters for a dam section under the storage level of $16 \mathrm{~m}$. Figure (1) shows the dam section in the absence of a filter where the flow line continues until it cuts the back of the dam, a situation that may cause a cumulative effect by doubling the weight of the soil portion mixed with water, which can lead to the displacement of this part and cause a failure of slip. Therefore, the safety factor is often low, as shown in the figure. However, it became necessary to use a filter of porous materials created horizontally or in a triangular shape at the back of the base of the dam, which contributes to controlling the progression of the flow line and the provisions of its safe exit from the dam's body to reduce the damage it may cause. Figures (1) to (2) explain a section dam by using a horizontal filter of different lengths. It appears that the increase in the length of the filter will contribute somewhat to reducing the distance of the flow line, which is reflected in the values of the safety factor by showing a noticeable increase even if it is below the required values, Figure (2).

\subsection{Pore Water Pressure}

Figure (3) shows the variation in pore water pressure (PWP) with the distance inside the dam body under the influence of different lengths of the filter $F(\mathrm{~m})$. A general increase in (PWP) from negative 
values with increasing distance can be observed. The use of a filter with lengths of $10 \mathrm{~m}$ and $15 \mathrm{~m}$ appears to have caused a noticeable increase in the (PWP) values to reach its maximum (52 kPa) at the distance of $23 \mathrm{~m}$, which then followed by a decrease to zero at distance from $33 \mathrm{~m}$ up to the toe of the dam. As for the rest of the filter lengths, the results showed a noticeable increase in the pressure values from negative till the distance of $22 \mathrm{~m}$ beyond which to zero up to the toe of the dam. It can be seen from the figure (4), that for all lengths of filter, the (PWP) values are increasing uniformly up to a distance of $25 \mathrm{~m}$, after which, a uniform drop occurred toward the dam toe. The pore water pressure (PWP) for all filter lengths are varied uniformly toward their maximum values at a distance of $38 \mathrm{~m}$ then lowered as the distance increased more than $38 \mathrm{~m}$ up to dam toe as shown in figure (5). The filter with length $10 \mathrm{~m}$ shows less effect on values of (PWP) when compared with other values. Figure (6) indicates that for all filter lengths, the (PWP) is increased with distance up to $50 \mathrm{~m}$ which then decreased toward dam toe. Mostly, the filter lengths have no effective influences on (PWP) values except at $(\mathrm{F}=15 \mathrm{~m})$ which caused an increase in values in comparison with other considered filter lengths.

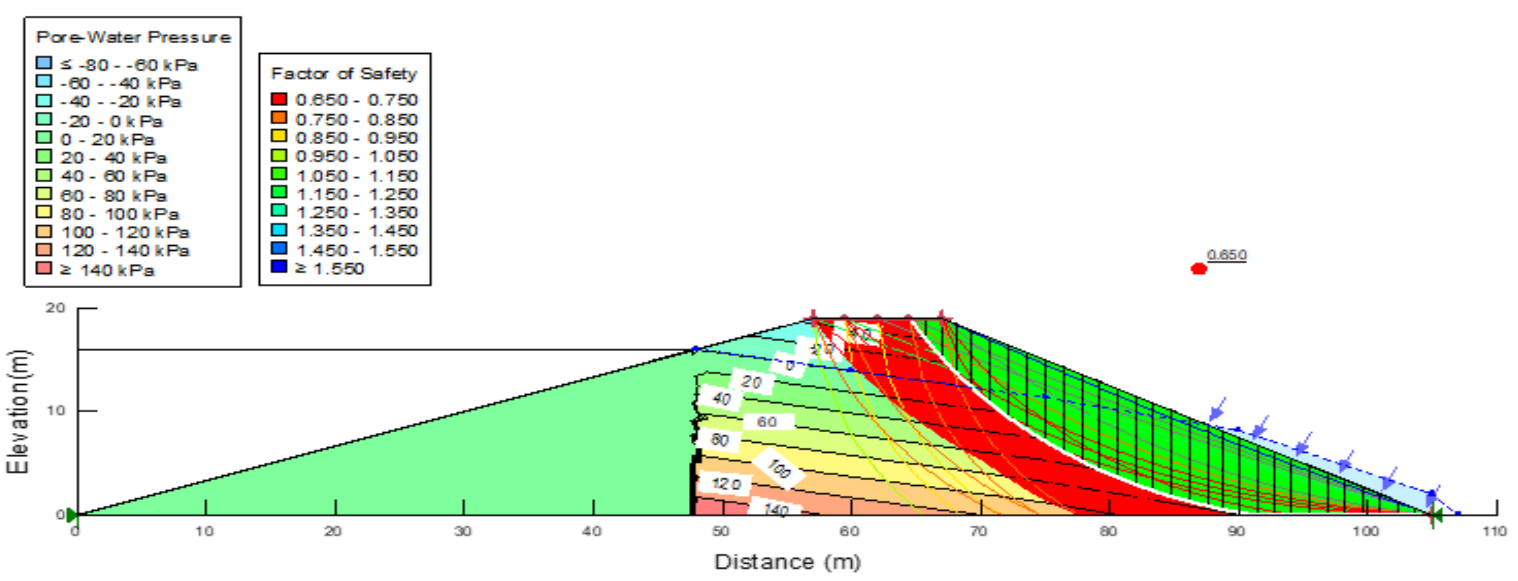

Figure (1): earth dam, $\mathrm{H}=16 \mathrm{~m}$ and Filter Length $=0 \mathrm{~m}$

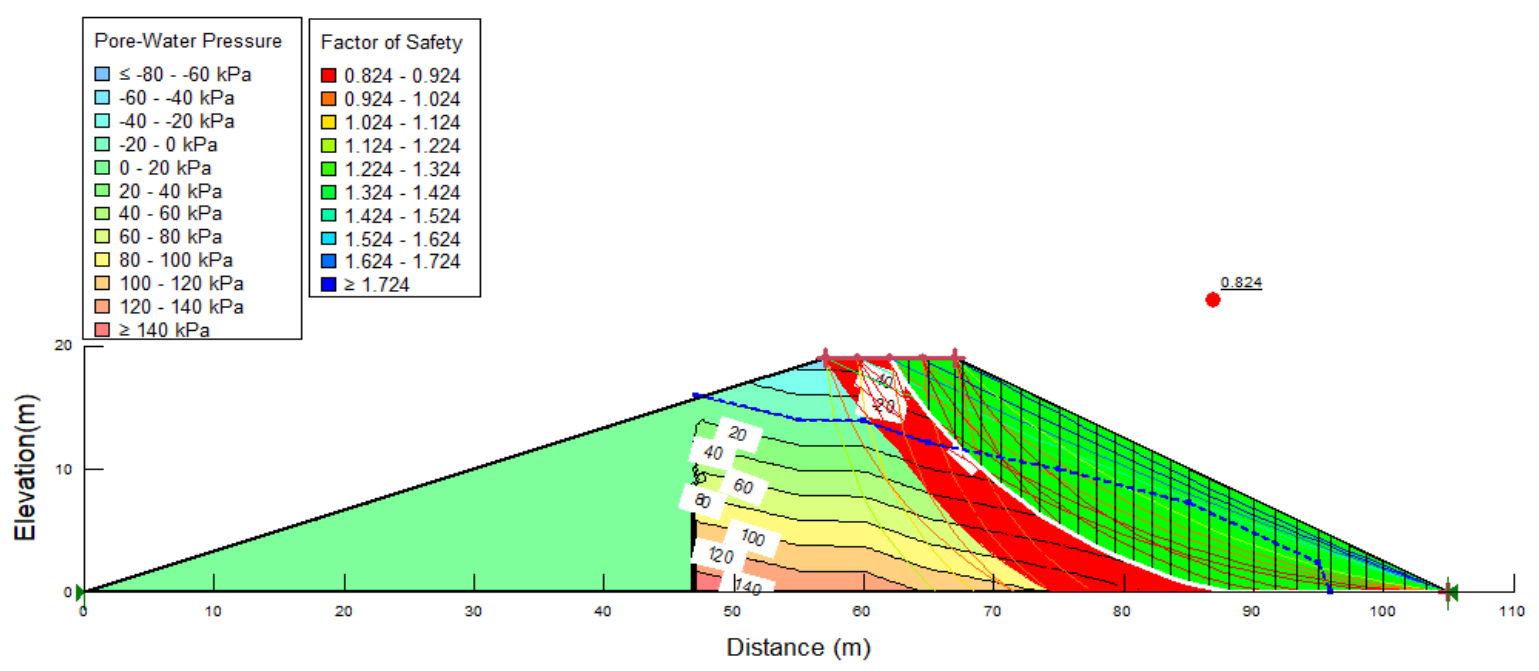

Figure (2): Earth dam, $\mathrm{H}=16 \mathrm{~m}$, and Filter Length $\mathrm{F}=10 \mathrm{~m}$. 
Figure (3) shows the variation in pore water pressure (PWP) with the distance inside the dam body under the influence of different lengths of the filter $F(\mathrm{~m})$. A general increase in (PWP) from negative values with increasing distance can be observed. The use of a filter with lengths of $10 \mathrm{~m}$ and $15 \mathrm{~m}$ appears to have caused a noticeable increase in the (PWP) values to reach its maximum (52 kPa) at the distance of $23 \mathrm{~m}$, which then followed by a decrease to zero at distance from $33 \mathrm{~m}$ up to the toe of the dam. As for the rest of the filter lengths, the results showed a noticeable increase in the pressure values from negative till the distance of $22 \mathrm{~m}$ beyond which to zero up to the toe of the dam. It can be seen from the figure (4), that for all lengths of filter, the (PWP) values are increasing uniformly up to a distance of $25 \mathrm{~m}$, after which, a uniform drop occurred toward the dam toe. The pore water pressure (PWP) for all filter lengths are varied uniformly toward their maximum values at a distance of $38 \mathrm{~m}$ then lowered as the distance increased more than $38 \mathrm{~m}$ up to dam toe as shown in figure (5). The filter with length $10 \mathrm{~m}$ shows less effect on values of (PWP) when compared with other values. Figure (6) indicates that for all filter lengths, the (PWP) is increased with distance up to $50 \mathrm{~m}$ which then decreased toward dam toe. Mostly, the filter lengths have no effective influences on (PWP) values except at $(\mathrm{F}=15 \mathrm{~m})$ which caused an increase in values in comparison with other considered filter lengths.

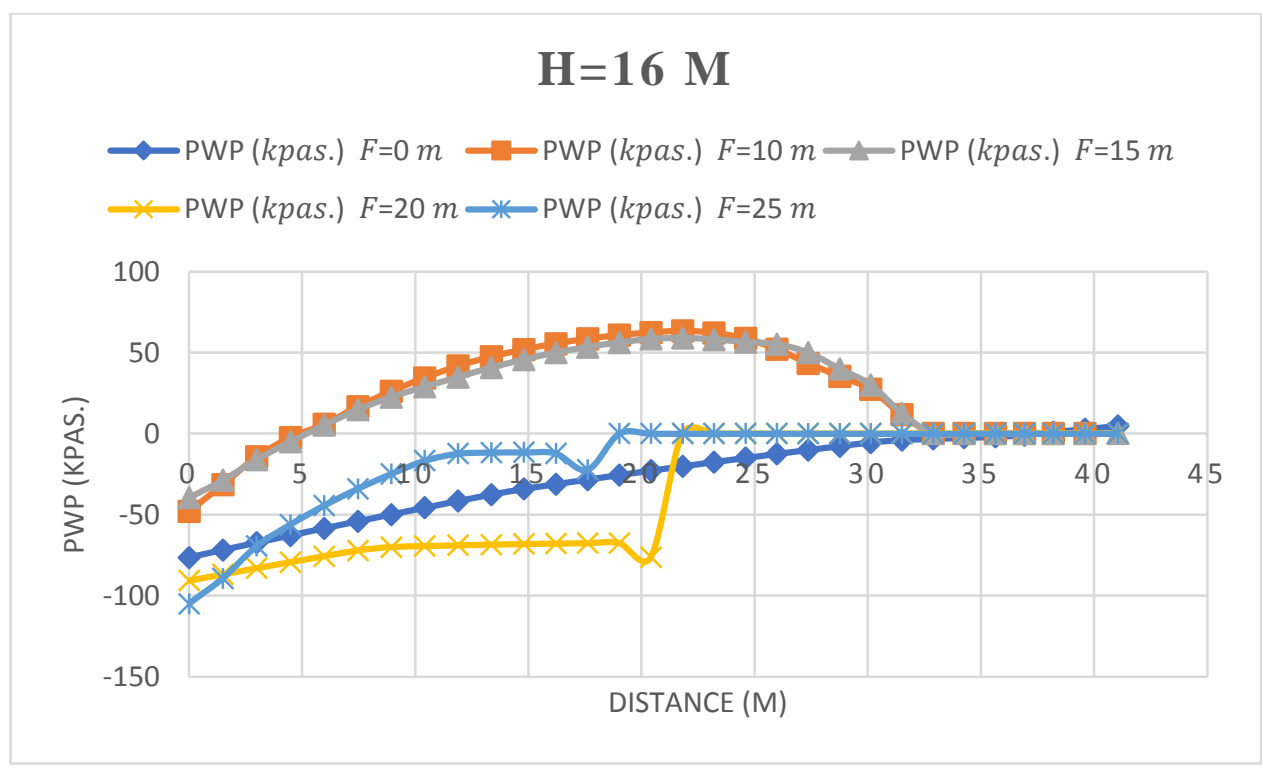

Figure (3): Variation of Pore water pressure for $\mathrm{H}=16 \mathrm{~m}$. 


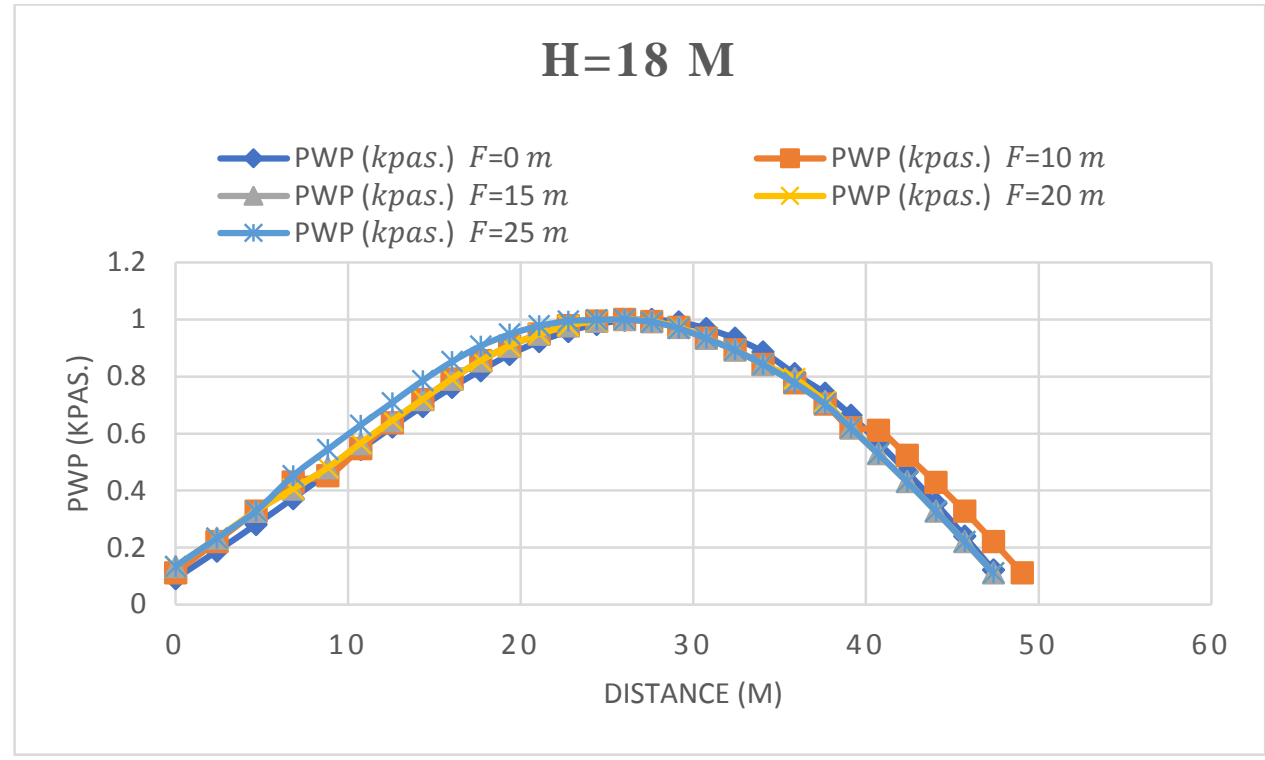

Figure (4): Variation of Pore water pressure for $\mathrm{H}=18 \mathrm{~m}$.

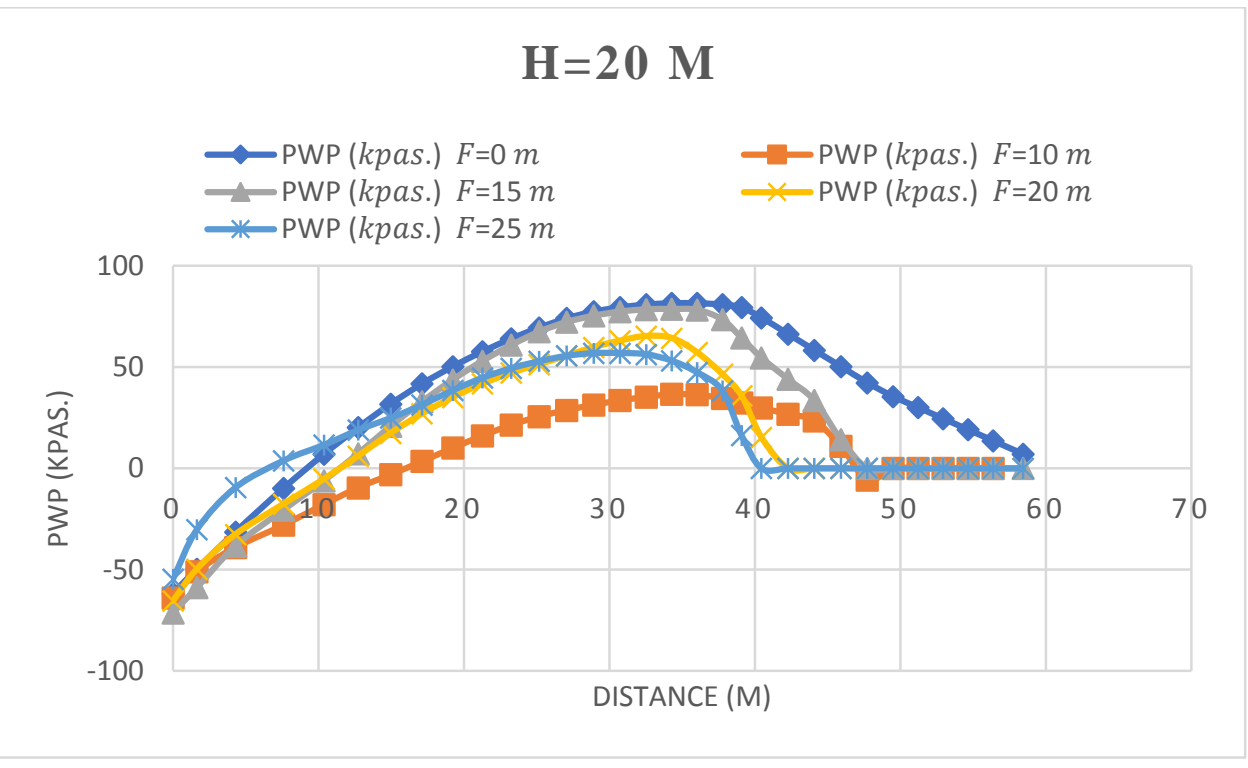

Figure (5): Variation of Pore water pressure for $\mathrm{H}=20 \mathrm{~m}$.

\subsection{Normal Forces}

Figure (7) represents the influences of different filter lengths on the values of normal forces along the downstream failure arc. It can be seen that for filter lengths $10 \mathrm{~m}, 15 \mathrm{~m}$, and $25 \mathrm{~m}$, the normal force $(\mathrm{N})$ increases with the distance and the highest values are indicated at distance $26 \mathrm{~m}$, beyond which the values are dropped toward the dam toe. For a filter of $20 \mathrm{~m}$ long or more, the $(\mathrm{N})$ values are seen to be invariant and no significant effect of filter length is observed. Figure (8) indicates that as a distance increased up to $32 \mathrm{~m}$, the normal forces are increased to a maximum value $(150 \mathrm{kPa})$. The $(\mathrm{N})$ values are then decreased for a distance of more than $32 \mathrm{~m}$ to the dam toe. The results show that the (N) values are independent of filter length variation. Figure (9) show that with exception of filter lengths of $10 \mathrm{~m}$ and $15 \mathrm{~m}$, the normal forces at $\mathrm{H}=20 \mathrm{~m}$ are increased as distance increased up to 38 
$\mathrm{m}$, which then turned to be less up to dam toe. Slight differences in normal force values for different filter lengths are indicated as distance increased up to $38 \mathrm{~m}$.

Figure (10) shows that for all filter lengths, the values of normal force are increased as distance increases to $60 \mathrm{~m}$ and then dropped toward the dam toe. It seems, that only a filter of $15 \mathrm{~m}$ length has relatively less effect on values of $(\mathrm{N})$.

Observing the results presented above shows that a length of the filter of $10 \mathrm{~m}$ is the most effective in increasing the values of (PWP), $(\mathrm{N})$, and even shear stress $(\tau)$, as shown next.

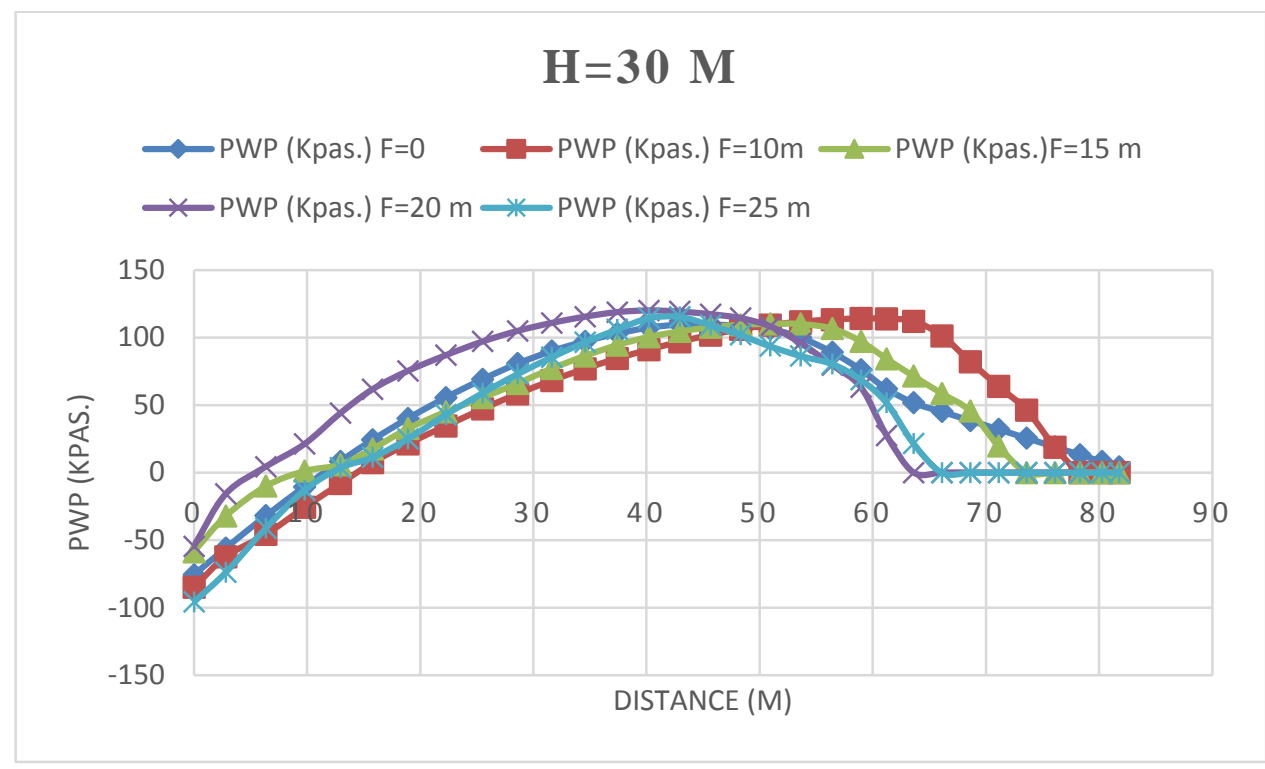

Figure (6): Variation of Pore water pressure for $\mathrm{H}=30 \mathrm{~m}$.

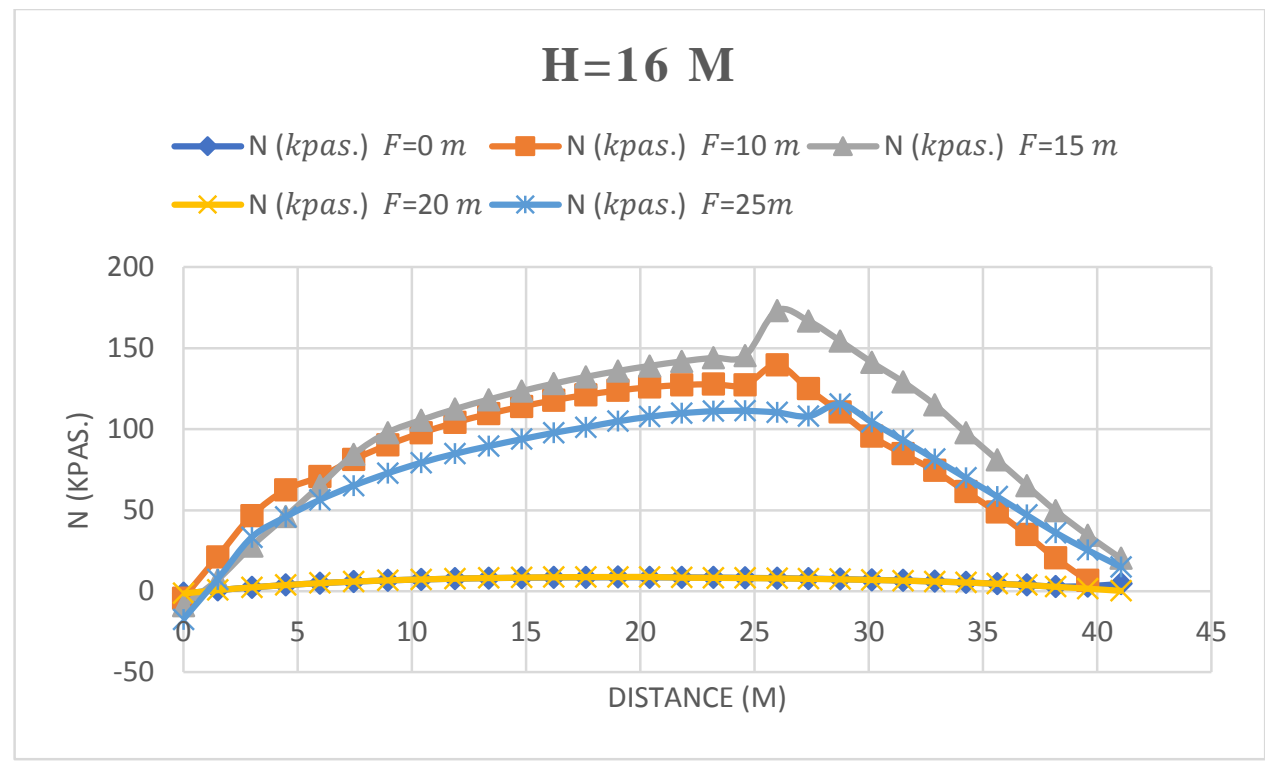

Figure (7): Variation of normal force for $\mathrm{H}=16 \mathrm{~m}$. 


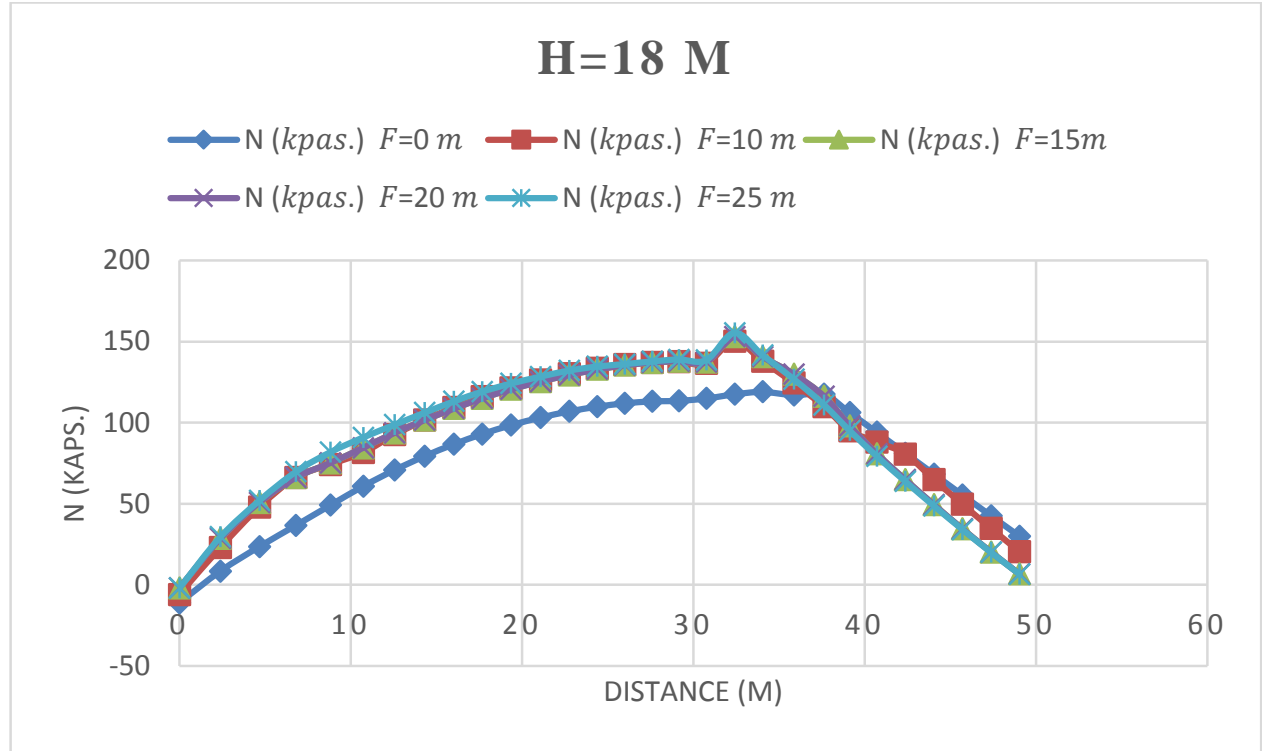

Figure (8): Variation of normal force for $\mathrm{H}=18 \mathrm{~m}$.

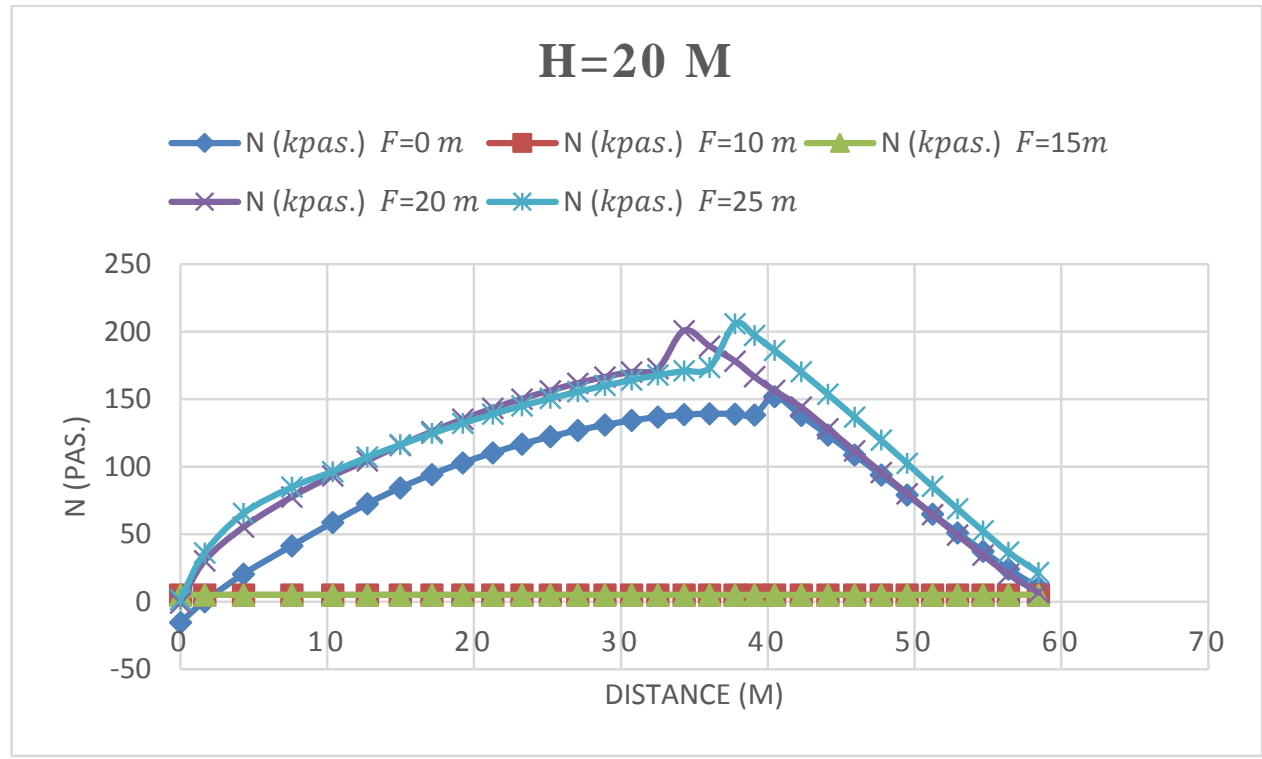

Figure (9): Variation of normal force for $\mathrm{H}=20 \mathrm{~m}$. 


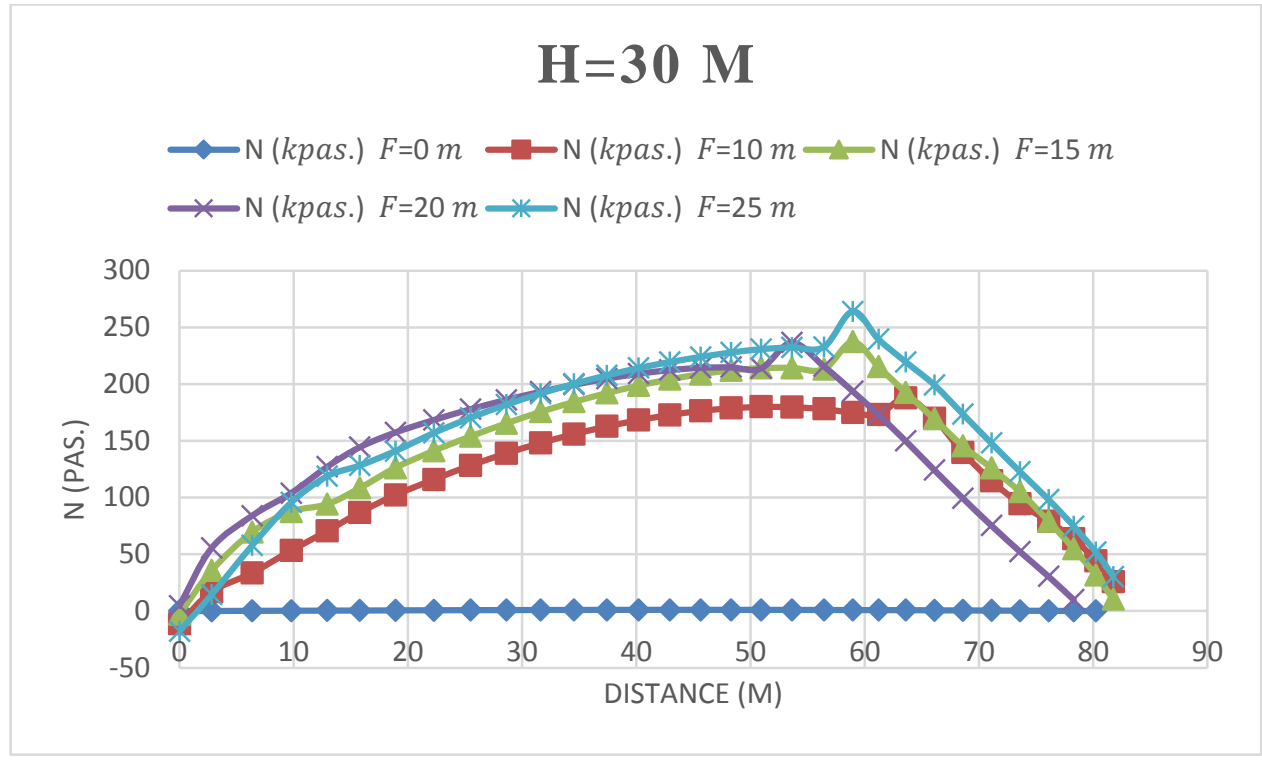

Figure (10): Variation of normal force for $\mathrm{H}=30 \mathrm{~m}$.

\subsection{Shear Stress}

Figure (11) indicates that for filter lengths $10 \mathrm{~m}, 15 \mathrm{~m}$, and $25 \mathrm{~m}$, the shear stress $(\tau)$ increase as the distance increases, and the highest values are indicated at distance $26 \mathrm{~m}$ after which the values are reduced uniformly toward the dam toe. In the case of filter lengths $0 \mathrm{~m}$ and $20 \mathrm{~m}$, a general reduction in $(\tau)$ values can be observed up to the toe of the dam. The variation of shear stress with distance for various filter lengths is shown in figure (12). The figure shows some fluctuation in the shear stress distribution behavior with a clear effect of the length of the filter reflected in the causing of relative discrepancy in the values. The results showed a slight increase in shear stress values up to a distance of $32 \mathrm{~m}$, and then a relatively sharp decline towards the dam toe is observed. The figure also indicates that using a filter with a length of $25 \mathrm{~m}$ caused a noticeable increase in shear stress values. Figure (13) shows that as the distance is increased by more than $38 \mathrm{~m}$, the values of shear stress are decreased toward dam toe. It can also be seen from the figure that a filter length of $25 \mathrm{~m}$ causing the highest value ( $\tau=75$ Kpas.). Figure (14) indicates that shear force values are varied uniformly with distance up to $60 \mathrm{~m}$ and then some fluctuations are observed for the remaining distance toward dam toe. The highest values of shear force are obtained at a filter length of $15 \mathrm{~m}$. 


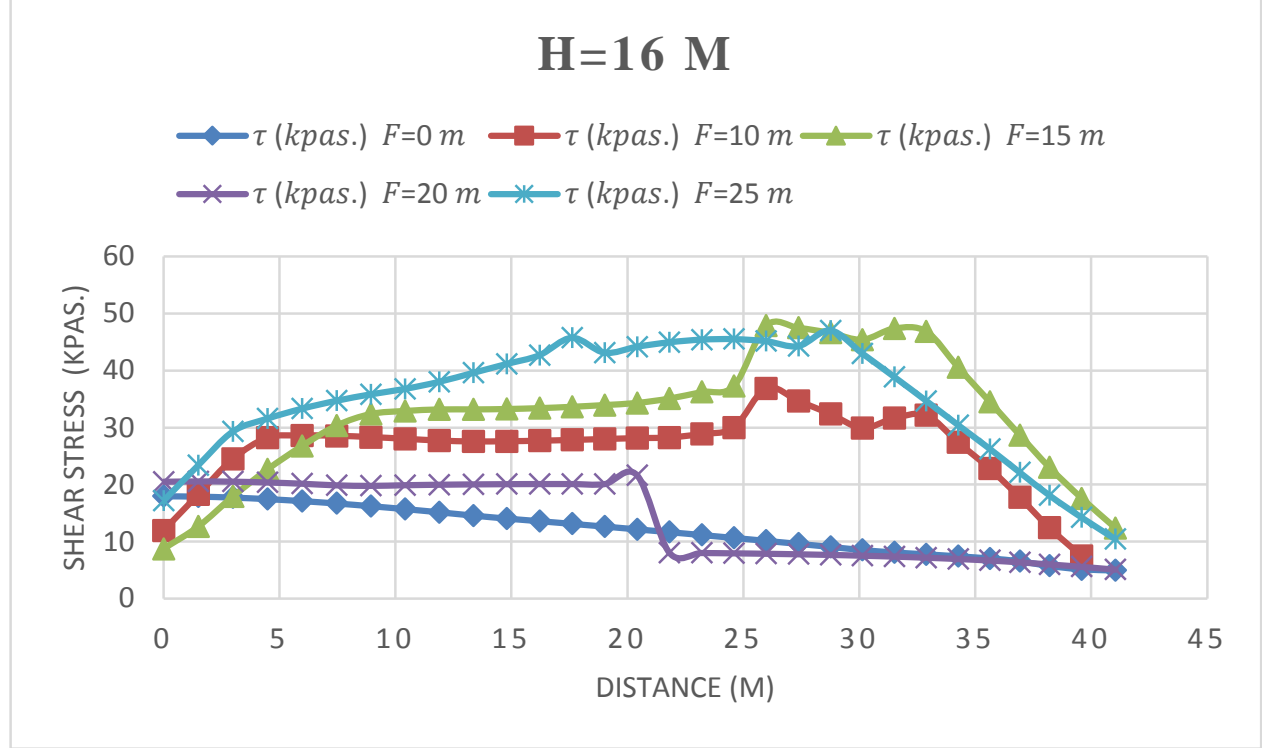

Figure (11): Variation of shear force for $\mathrm{H}=16 \mathrm{~m}$.

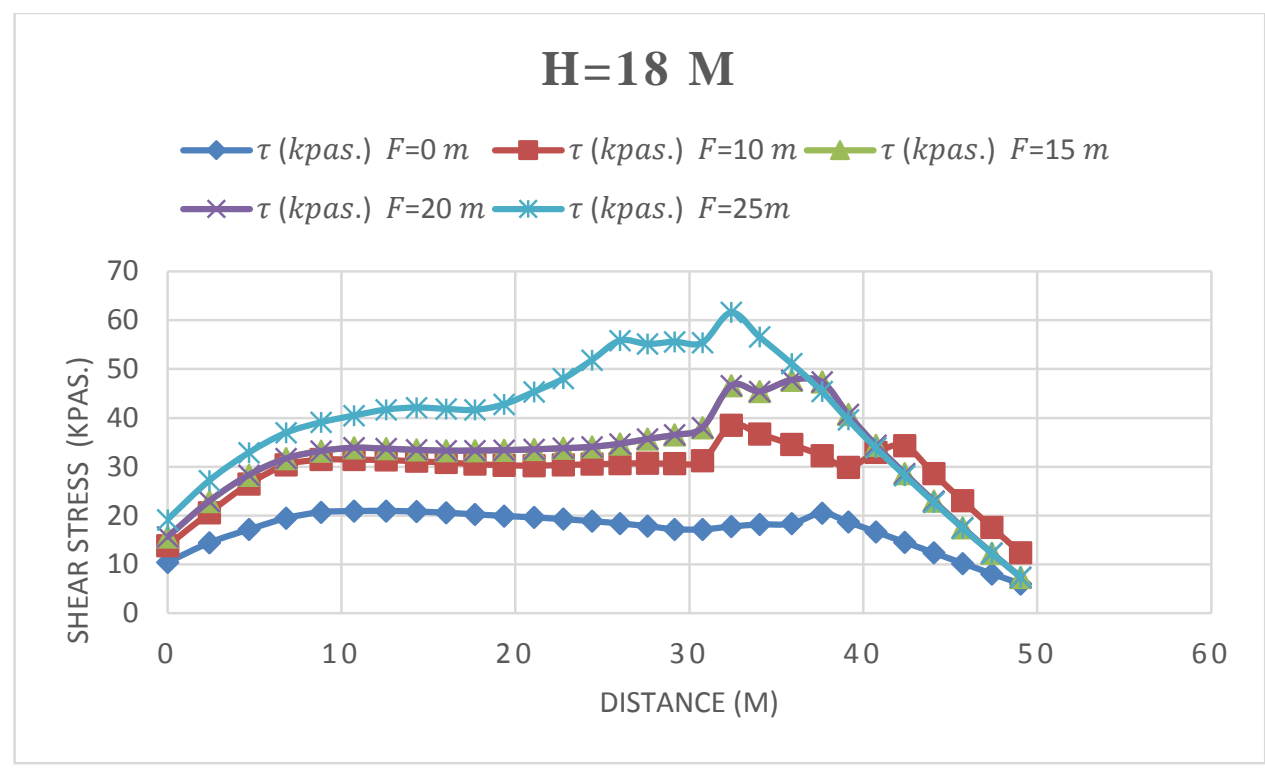

Figure (12): Variation of shear force for $\mathrm{H}=18 \mathrm{~m}$. 
Eurasian Journal of Science \& Engineering

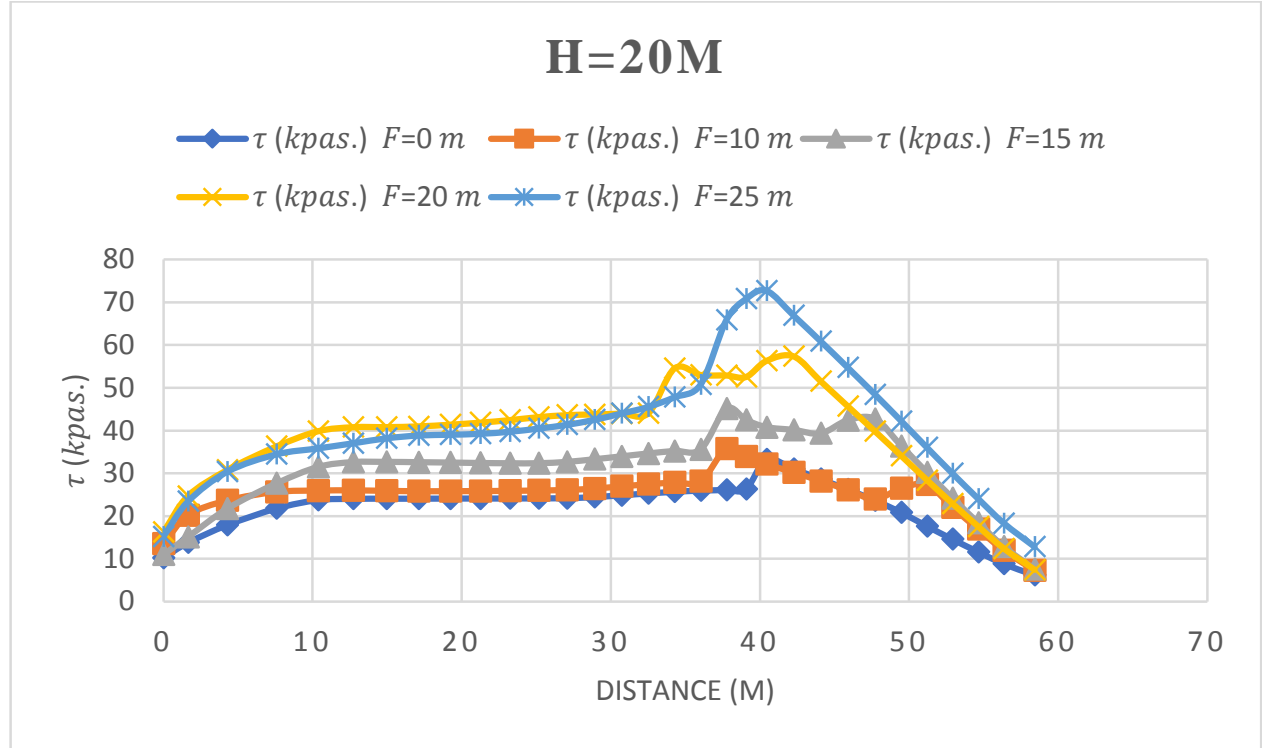

Figure (13): Variation of shear force for $\mathrm{H}=20 \mathrm{~m}$.

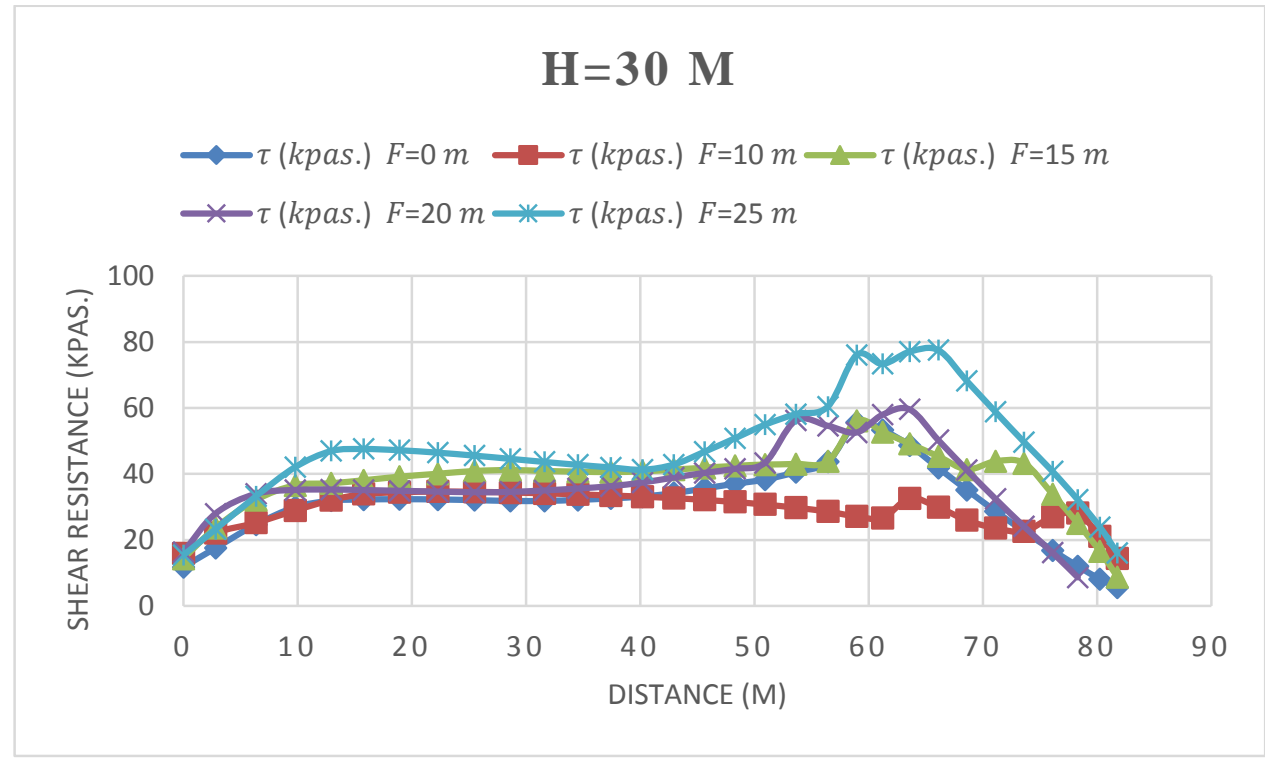

Figure (14): Variation of shear force for $\mathrm{H}=30 \mathrm{~m}$.

The analysis of the earth dam section with water head $(\mathrm{H}=30 \mathrm{~m})$ showed that the increase in filter length slightly increases the safety factor as shown in Table (1), in which all values are still below the permissible limits. 
Table 1: Effect of filter length on sliding safety factor for different $\mathrm{H}$.

\begin{tabular}{|l|l|l|l|l|}
\hline Filter Length $(\mathrm{m})$ & F.S $(\mathrm{H}=16 \mathrm{~m})$ & F.S $(\mathrm{H}=18 \mathrm{~m})$ & F.S $(\mathrm{H}=20 \mathrm{~m})$ & F.S $(\mathrm{H}=30 \mathrm{~m})$ \\
\hline 0 & 0.65 & 0.628 & 0.999 & 0.629 \\
\hline 10 & 0.824 & 0.815 & 0.899 & 0.602 \\
\hline 15 & 0.931 & 0.92 & 1.12 & 0.699 \\
\hline 20 & 1.058 & 0.95 & 1.3 & 0.68 \\
\hline 25 & 1.193 & 1.127 & 1.298 & 0.821 \\
\hline
\end{tabular}

\section{Seepage Analysis}

The current study also examines the effect of filter length on the behavior of exudation lines and the amount of flow coming from a reservoir into the dam's body under the influence of different levels of storage water. The analysis is conducted by using the GeoStudio software and the results are shown for each headwater storage considered in the current study. The effect of anisotropy on the seepage flow through the earth dam section is illustrated in figures. The figures indicate that the greater the degree of anisotropy, that is, the greater the magnitude of the ratio of the horizontal to vertical permeability the more distorted the flow net becomes when it is redrawn on the natural dam section. The figures also indicate that the greater the degree of anisotropy the closer the line of seepage to move toward the downstream slope of the dam. Figures (15 up to 28), indicate the behavior of pressure head and pore water pressure distribution through the section of the earthly dam of a 16-meter storage level and some of the earthly dam of an 18-meter. The effect of several values of the length of the filter was tested and the flow value into the dam's body was estimated. The figures illustrate that as the length of the filter increases the amount of seepage flow increases.

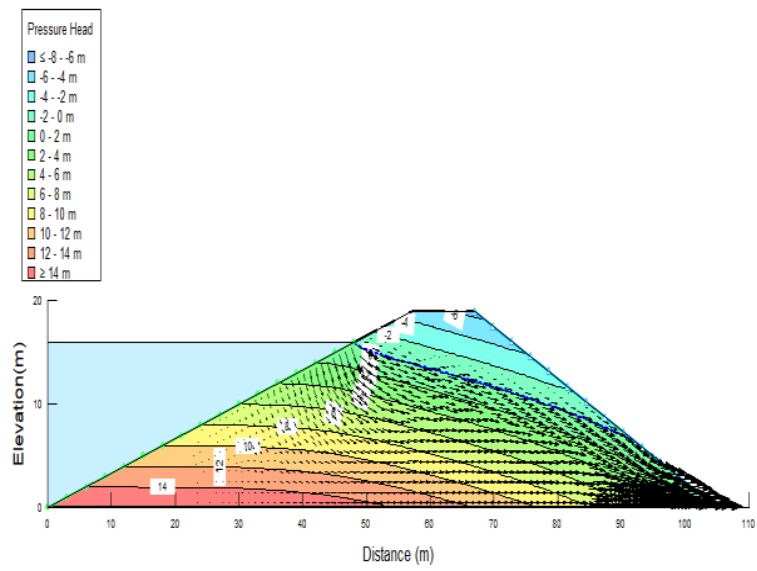

Figure (15): Pressure head within earth dam,

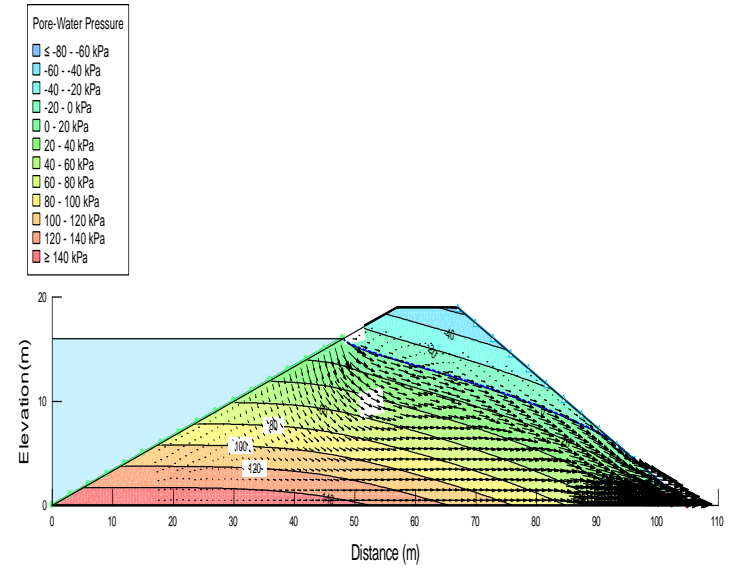

Figure (16): PWP within earth dam

$\mathrm{H}=16 \mathrm{~m}$ and Filter Length $=0 \mathrm{~m}$ 


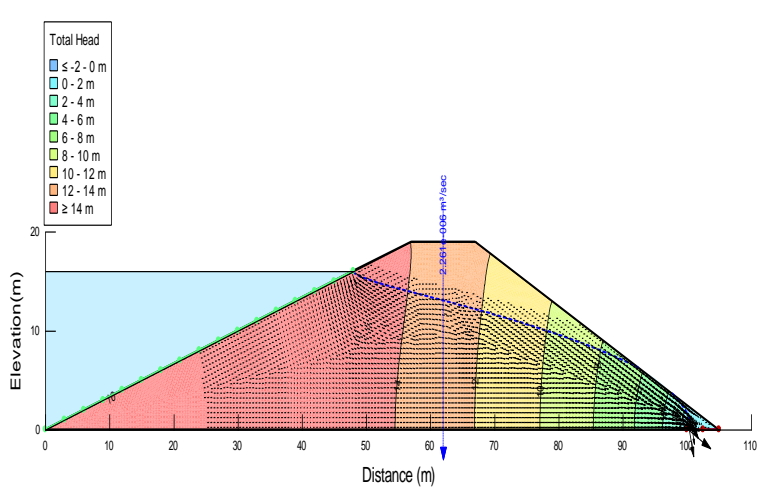

Figure (17): Pressure head within earth dam,

$\mathrm{H}=16 \mathrm{~m}$, and Filter Length $=5 \mathrm{~m}$

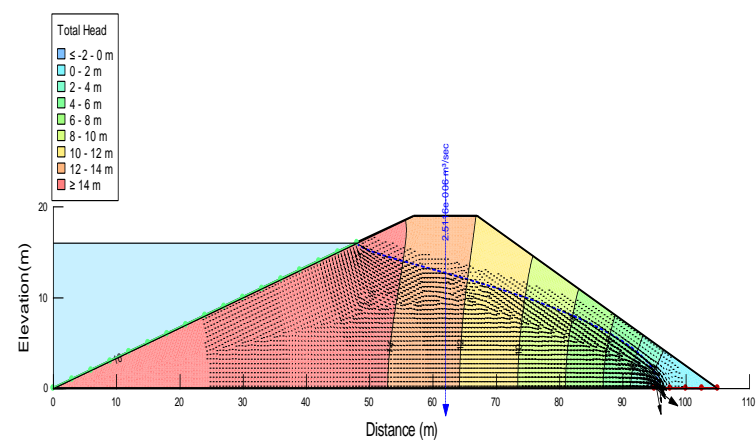

Figure (19): Pressure head within earth dam,

$\mathrm{H}=16 \mathrm{~m}$, and Filter Length $=10 \mathrm{~m}$

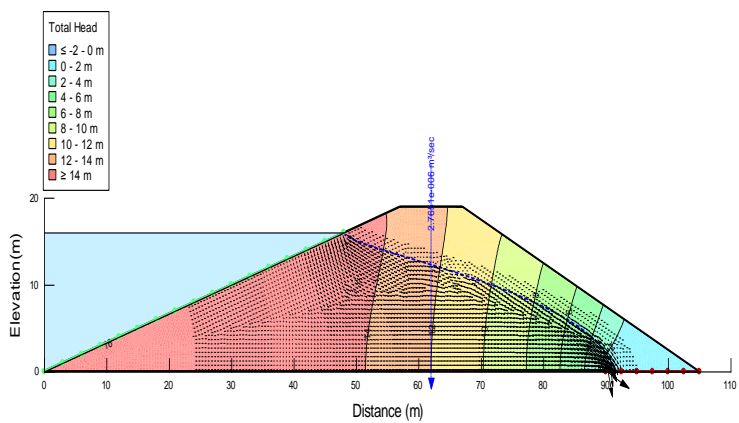

Figure (21): Pressure head within earth dam,

$\mathrm{H}=16 \mathrm{~m}$, and Filter Length $=20 \mathrm{~m}$

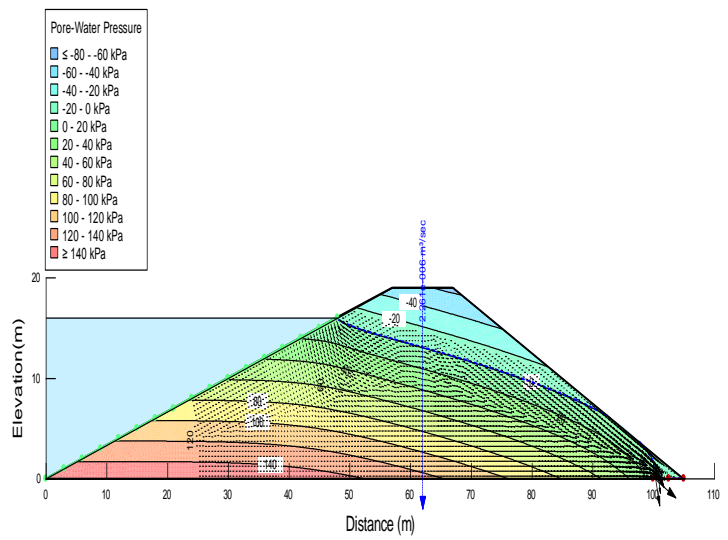

Figure (18): PWP within earth dam, $\mathrm{H}=16 \mathrm{~m}$, and Filter Length $=5 \mathrm{~m}$.

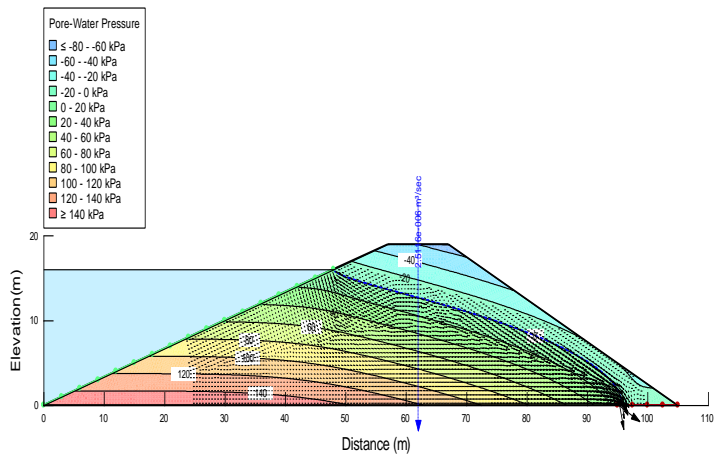

Figure (20): PWP within earth dam, $\mathrm{H}=16 \mathrm{~m}$, and Filter Length $=10$

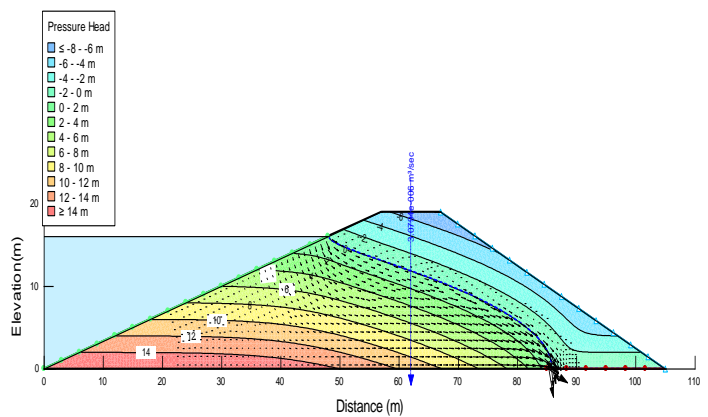

Figure (22): PWP within earth dam $\mathrm{H}=16 \mathrm{~m}$, and Filter Length $=20 \mathrm{~m}$ 


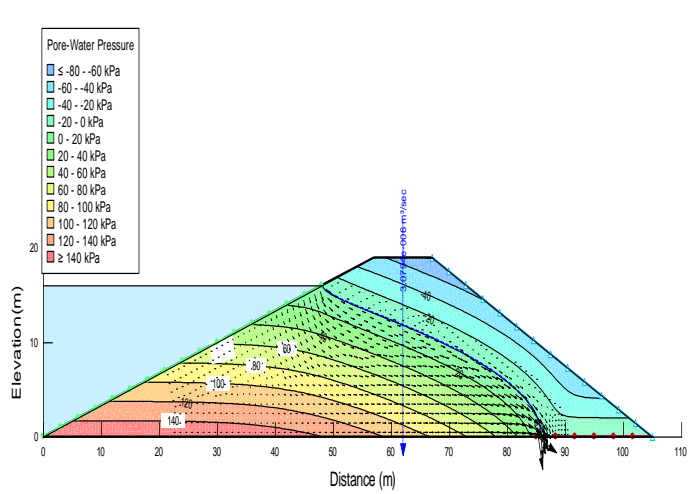

Figure (23): Pressure head within earth dam,

$\mathrm{H}=16 \mathrm{~m}$, and Filter Length $=25 \mathrm{~m}$

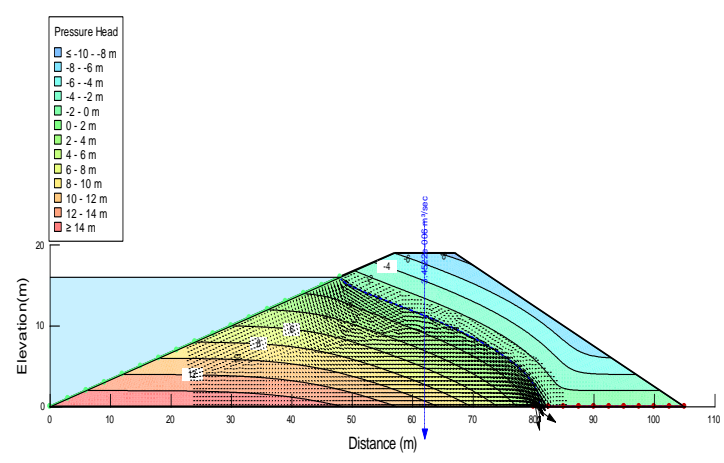

Figure (25): Pressure head within earth dam,

$H=16 \mathrm{~m}$, and Filter Length $=30 \mathrm{~m}$

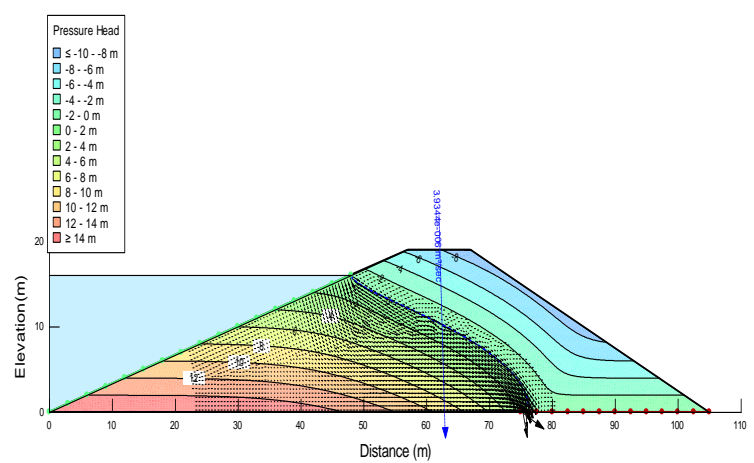

Figure (27): Pressure head within earth dam,

$\mathrm{H}=18 \mathrm{~m}$, and Filter Length $=30 \mathrm{~m}$

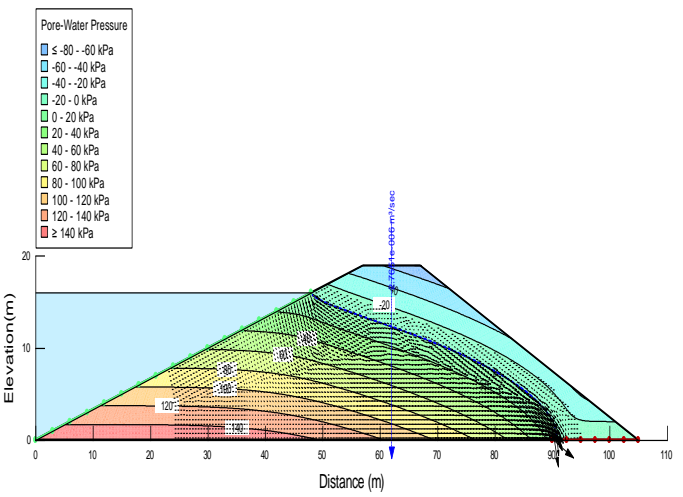

Figure (24): PWP within earth dam

$\mathrm{H}=16 \mathrm{~m}$, and Filter Length $=25 \mathrm{~m}$

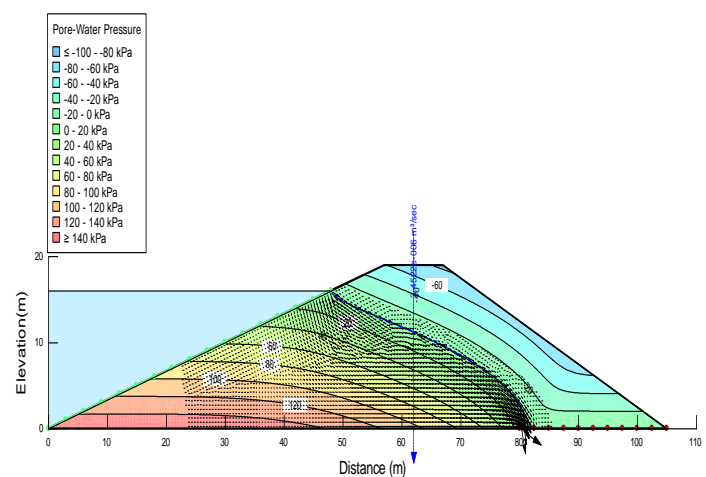

Figure (26): PWP within earth dam

$\mathrm{H}=16 \mathrm{~m}$, and Filter Length $=30 \mathrm{~m}$

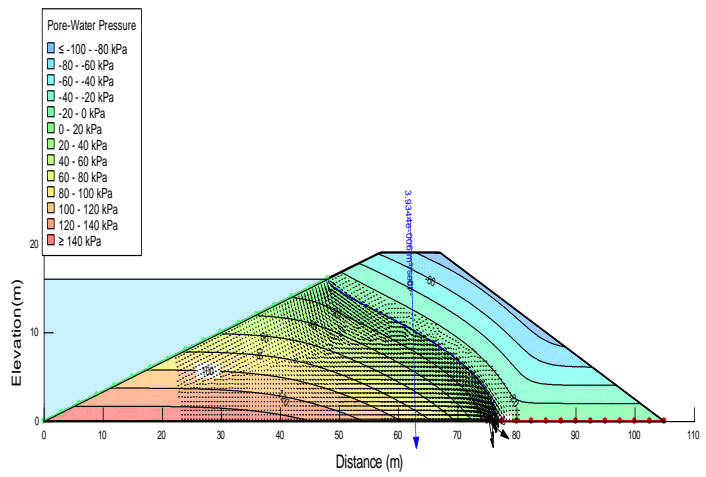

Figure (28): PWP within earth dam

$\mathrm{H}=18 \mathrm{~m}$, and Filter Length $=30 \mathrm{~m}$

Figure (29) shows the variation of pore water pressure with a distance at $\mathrm{H}=16 \mathrm{~m}$. It can be seen from this figure that the values of PWP are started from zero and dropped uniformly toward their minimum 
values at a distance around $43 \mathrm{~m}$. In general, the values of PWP are relatively high for filters with small length and decreased consequently as the length of filter increases.

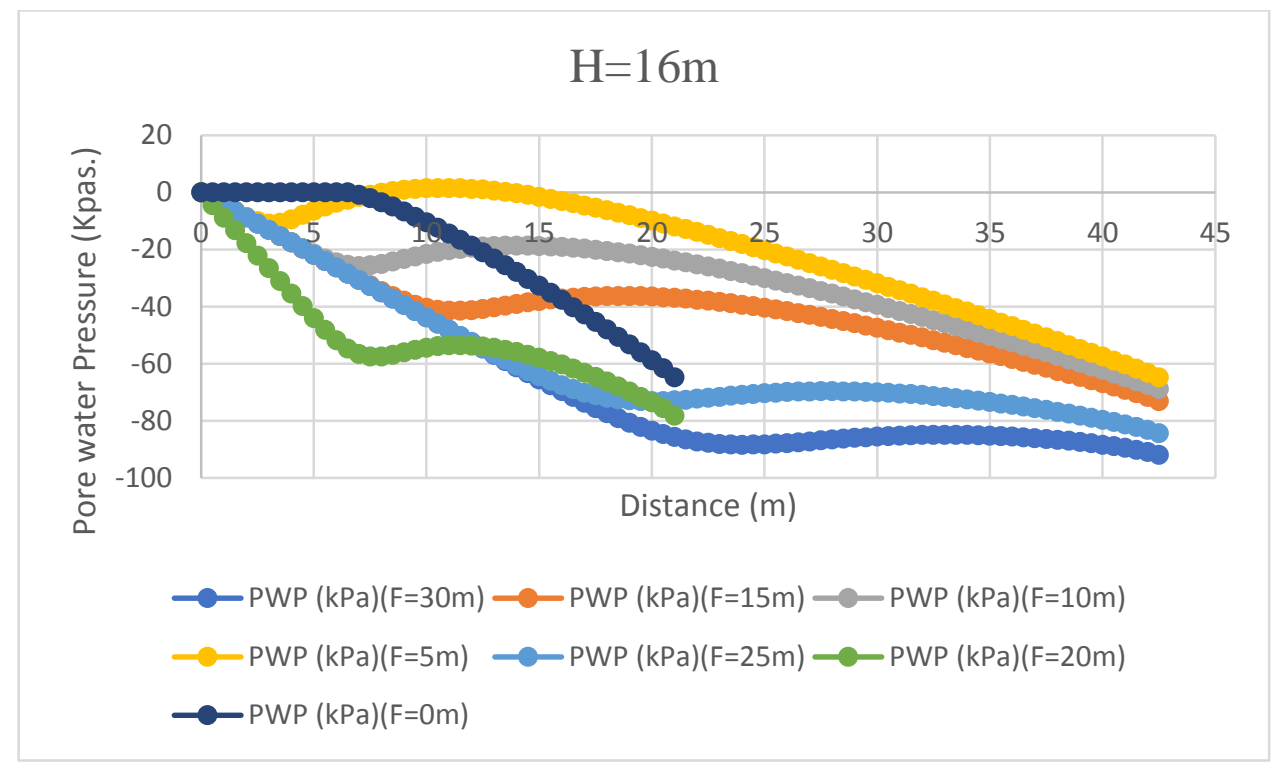

Figure(29): variation of pore water pressure along with distance for different filter lengths

Figure (30) shows the variation of pore water pressure along with the distance at $\mathrm{H}=18 \mathrm{~m}$. The figure indicates that the values of PWP are started from zero and dropped uniformly toward their minimum values at a distance of around $48 \mathrm{~m}$. In general, the values of PWP are relatively high for filters with small length and decreased thus as the length of filter increases.

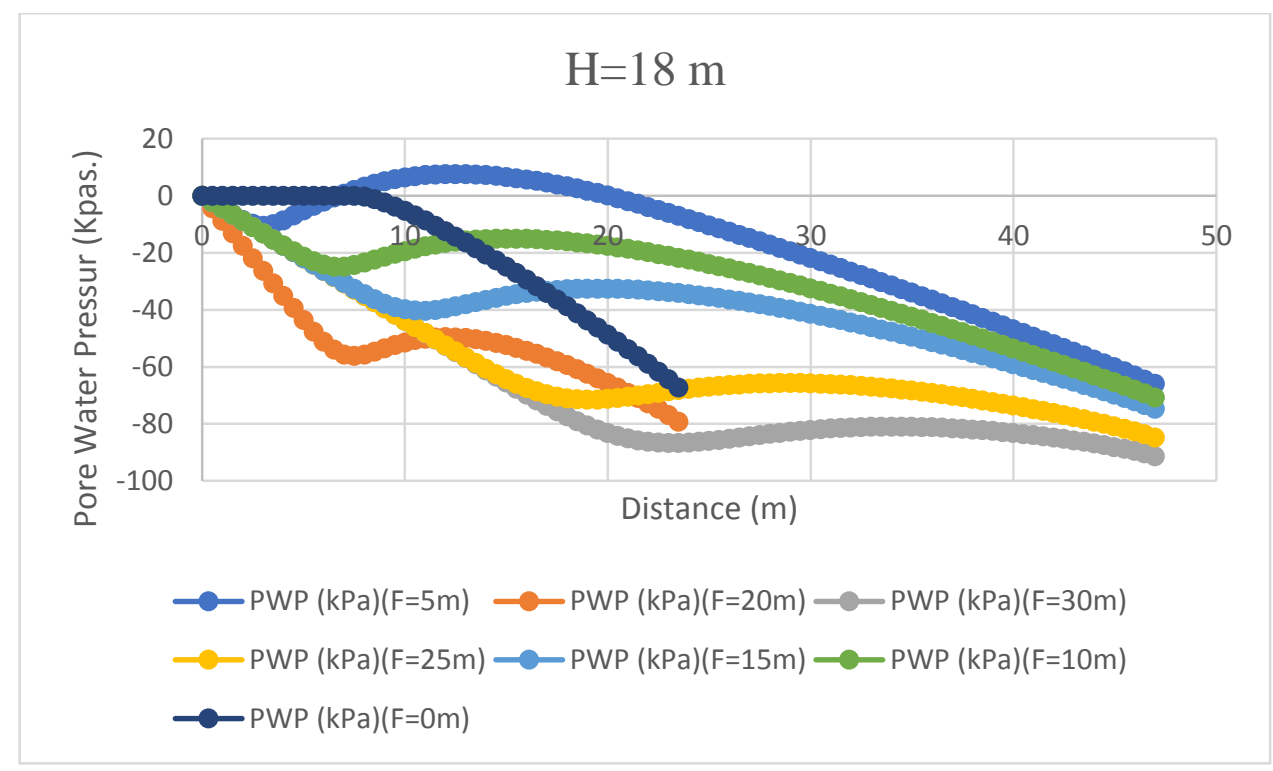

Figure(30): variation of pore water pressure along with distance for different filter lengths 
Figure (31) shows the variation of pore water pressure along with the distance at $\mathrm{H}=20 \mathrm{~m}$. It can be seen from this figure that the values of PWP are started from zero and dropped uniformly near their minimum values at a distance of about $55 \mathrm{~m}$. In general, the values of PWP are relatively high for filters with small length and decreased subsequently as the length of filter increases.

Figure ( 32 shows the variation of pore water pressure along with the distance at $\mathrm{H}=30 \mathrm{~m}$. It can be seen from this figure that the values of PWP are started from zero and throw down consistently toward their minimum values at a distance around $74 \mathrm{~m}$. In general, the values of PWP are relatively high for filters with small length and decreased consequently as the length of filter increases. However, the maximum values of PWP are produced in the case of no filter within the toe end of the earthen dam.

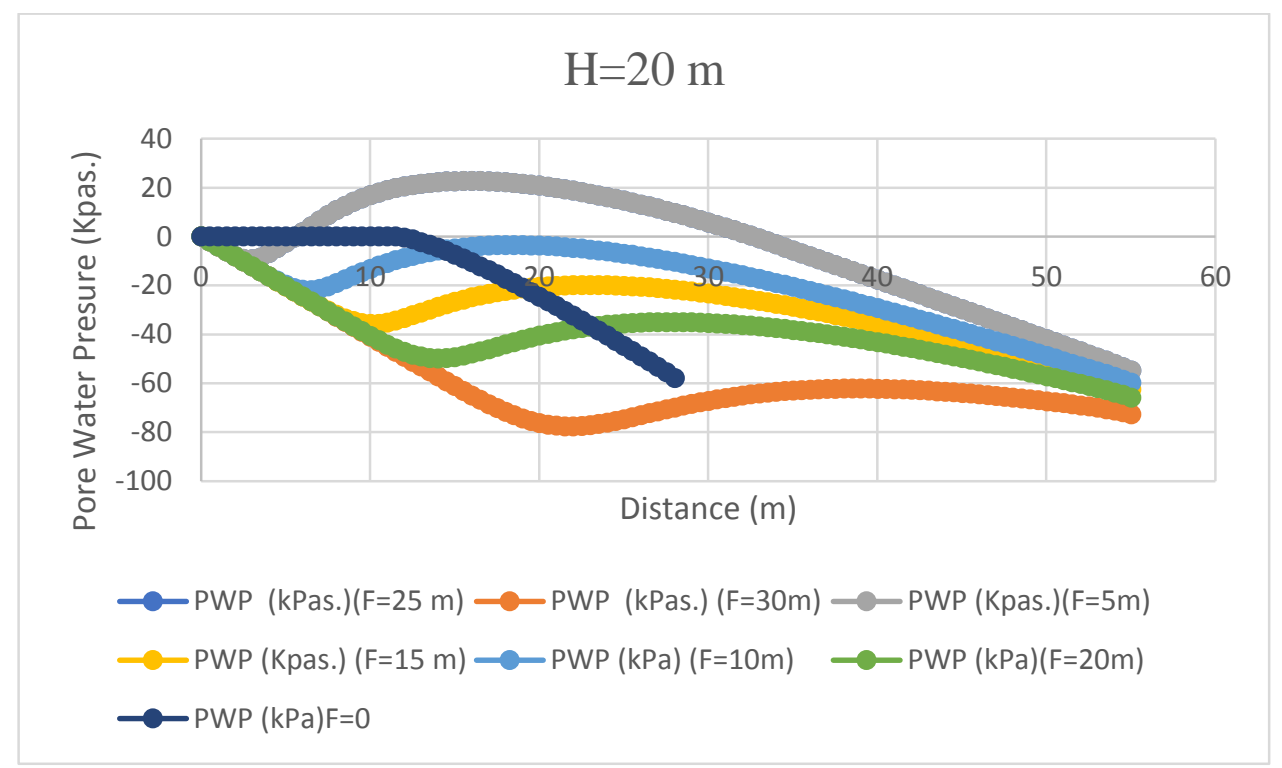

Figure(31): variation of pore water pressure along with distance for different filter length

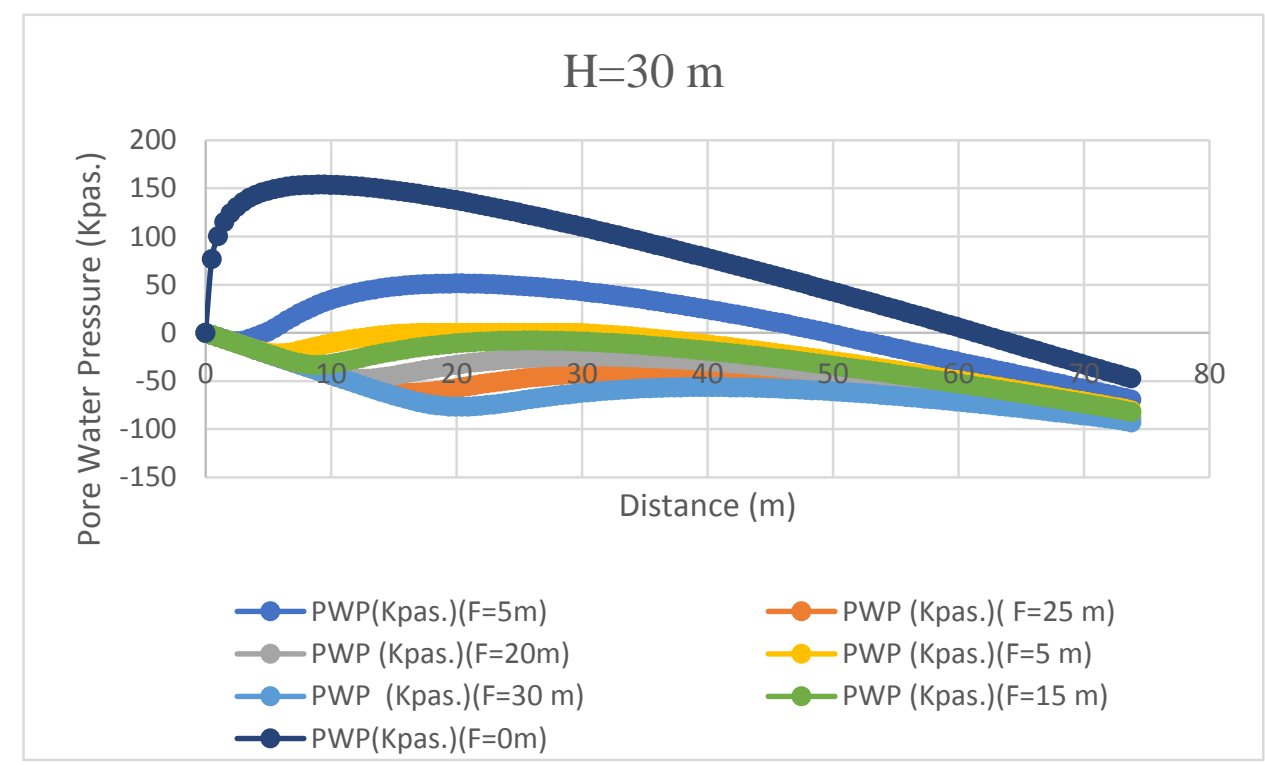

Figure(32): variation of pore water pressure along with distance for different filter length 


\section{Effects of Filter Length on Safety Factor}

Figure (33) shows the effect of filter length on the values of the safety factor for different storage water levels. It can be seen from the figure that for all values of $(\mathrm{H})$, the safety factor increases as the filter length increased with a slight discrepancy at $\mathrm{H}$ of $20 \mathrm{~m}$ and $30 \mathrm{~m}$.

\section{Effects of Filter Length on the Amount of Seepage Flow}

Figure (34) shows the effect of filter length on the values of the seepage flow rate for different storage water levels. It can be seen from the figure that for all values of $(\mathrm{H})$, the amount of seepage increases uniformly as the filter length increased. The figure has also been showing that the amount of seepage increased as H increased. Such behavior may be attributed that as the length of the filter increases the movement distance of flow toward the exit point will be short and caused an increase in the amount of flow within the dam body.

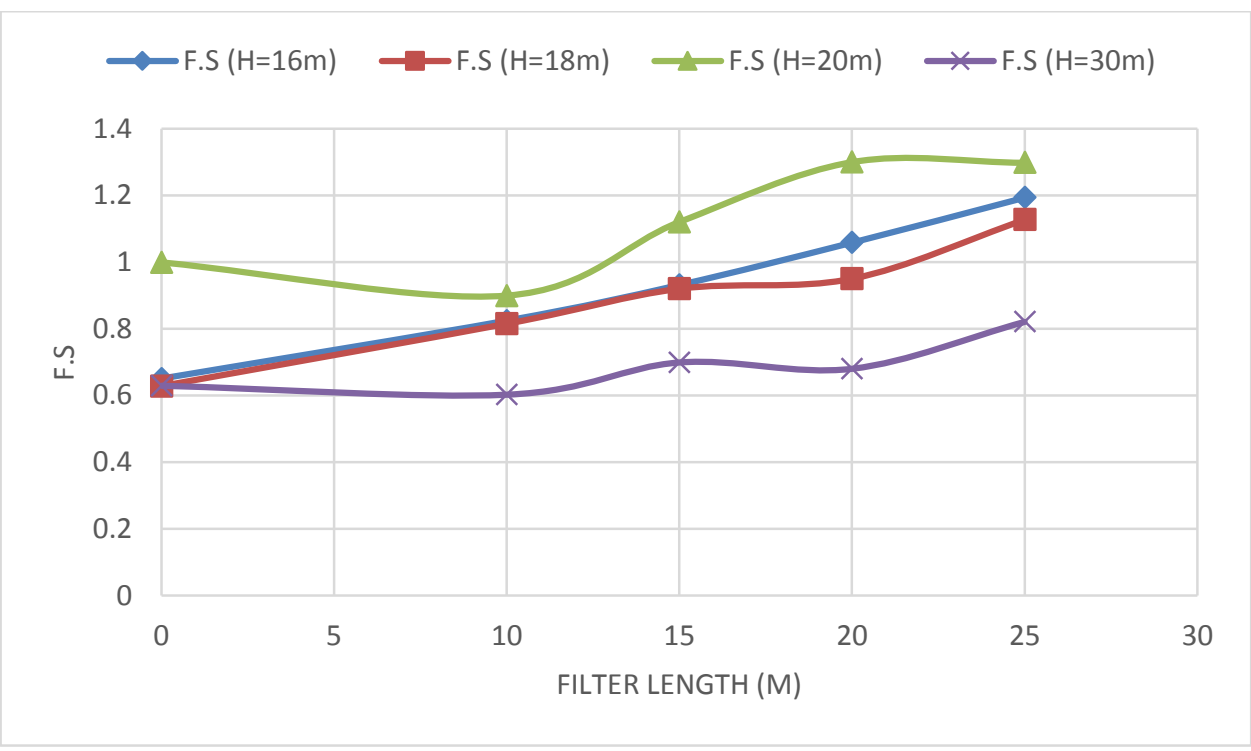

Figure(33): variation of pore water pressure along with distance for different filter lengths

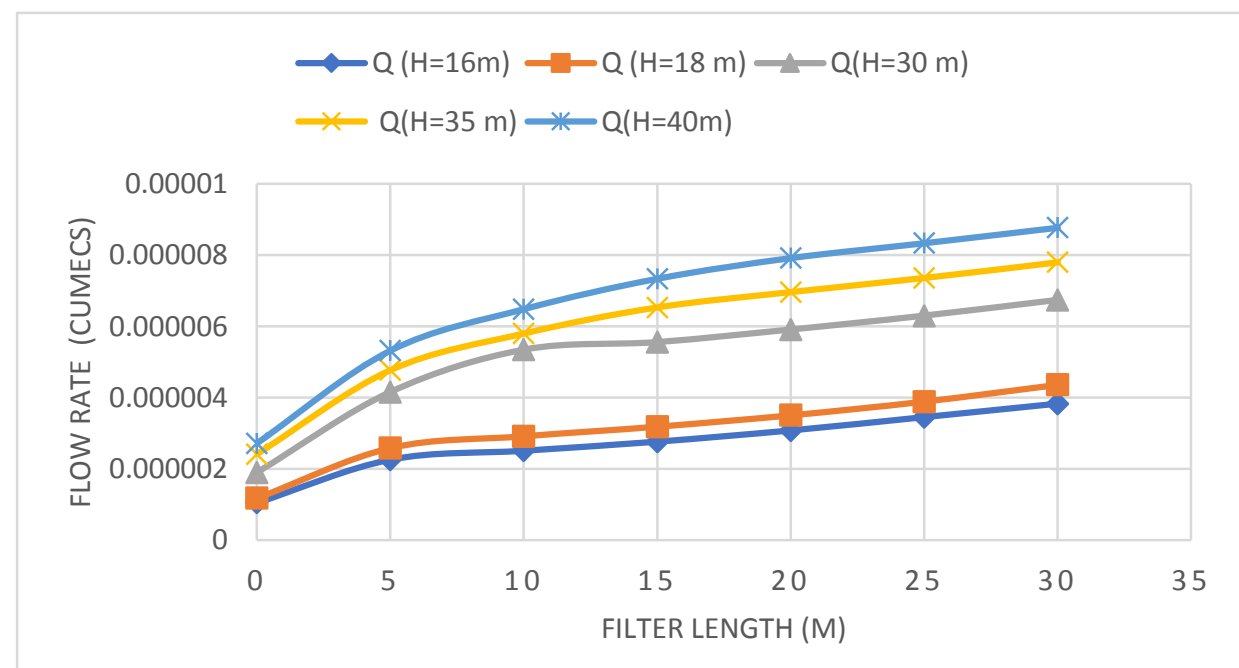

Figure(34): Effects of filter length on seepage flow amount inside earth dam body 


\section{Conclusion}

In this study, a program of geo-studio was used to analyze the earthen dam with various storage levels and sections. The effect of filter length on the safety factor due to downstream sliding of the dam as well as on the seepage rates inside the dam's body was studied. The results were discussed and the following conclusions were settled:

1-The general results showed that as filter length increased the factor of safety of D/S slope stability and the amount of seepage are increased.

2- At $\mathrm{H}=16 \mathrm{~m}$, the use of a filter with lengths of $10 \mathrm{~m}$ and $15 \mathrm{~m}$ seems to have caused an obvious increase in the (PWP) values to reach its maximum (52 kPa). Whereas the use of for filter lengths 10 $\mathrm{m}, 15 \mathrm{~m}$, and $25 \mathrm{~m}$, the shear stress and normal force $(\mathrm{N})$ increase as the distance increase, and the highest values are indicated at distance $26 \mathrm{~m}$.

3- At $\mathrm{H}=18 \mathrm{~m}$, for all lengths of the filter, the values of (PWP) and (N) increase uniformly up to a distance of $25 \mathrm{~m}$, after which, a uniform decrease in the direction of the dam toe occurred, while the shear stresses are fluctuating and showed a slight increase at a distance of $32 \mathrm{~m}$ especially in the case of using a $25 \mathrm{~m}$ filter, then a relatively sharp drop is observed towards the toe of the dam.

4-For $\mathrm{H}=20 \mathrm{~m}$, The pore water pressure (PWP) for all filter lengths are varied uniformly toward their maximum values at a distance of $38 \mathrm{~m}$ then lowered as a distance increased up to dam toe. The results have also been showing that expects of filter lengths of $10 \mathrm{~m}$ and $15 \mathrm{~m}$, the normal forces are increased as distance increased up to $38 \mathrm{~m}$, which then turned to be less up to dam toe. As distance increased more than $38 \mathrm{~m}$, the values of shear stress values are decreased toward dam toe. The results also showed that a filter length of $25 \mathrm{~m}$ causing the highest value of shear stress ( $\tau=75 \mathrm{Kpas}$.).

5- At $\mathrm{H}=30 \mathrm{~m}$, the results indicated that for all filter lengths, the (PWP) is increased with distance up to $50 \mathrm{~m}$ which then decreased toward dam toe. Mostly, the filter lengths have no effective influences on (PWP) values except for $(\mathrm{F}=15 \mathrm{~m})$ which caused an increase in values in comparison with other considered filter lengths. For all filter lengths, the values of normal force are increased as distance increases to $60 \mathrm{~m}$ and then dropped toward the dam toe. It seems, that only a filter of $15 \mathrm{~m}$ length has relatively less effect on values of $(\mathrm{N})$. The shear force values are varied uniformly with distance up to $60 \mathrm{~m}$ and then some fluctuations are observed for the rest distance toward dam toe. The highest values of shear force are arising as a result of a filter length of $15 \mathrm{~m}$.

\section{References}

Abbas, J. K. (2017). Determination of Flow through Homogeneous Earth Dams with Triangular Toe Filter. Tikrit Journal of Engineering Sciences, 24(1), 81-88.

Al-Labban, S. (2018). Seepage and Stability Analysis of the Earth Dams under Drawdown Conditions by using the Finite Element Method.

Chowhury, M. A., Kunitake, M., Kondo, F., Inagaki, H., Ogata, H., Saito, M., \& Kakuda, I. (1996, January). Estimation of the parameters of seepage through an earth dam. In The Sixth International Offshore and Polar Engineering Conference. International Society of Offshore and Polar Engineers.

Fei, K., \& Zhang, J.W. (2010). ABAQUS application in geotechnical engineering. Beijing: China Water Power Press. 
George, M., \& Annandale, G. W. (2006, January). Dam failure by rock scour: evaluation \& prevention (A Case Study). In Golden rocks, 2006, The 41 st US Symposium on Rock Mechanics (USRMS). American Rock Mechanics Association.

Griffiths, D. V., \& Lane, P. A. (1999). Slope stability analysis by finite elements. Geotechnique, 49(3), 387-403.

Luca, A. L., \& Pop, O. A. (2016). Earth dam stability-the analysis of filtration process. Scientific Papers-Series E-Land Reclamation Earth Observation \& Surveying Environmental Engineering, 5, 33-38.

Mishal, U. R., \& Khayyun, T. S. (2018). Stability analysis of an earth dam using the GEO-SLOPE model under different soil conditions. Engineering and Technology Journal, 36(5 Part (A) Engineering), 523-532.

Tatewar, S. P., \& Pawade, L. N. (2012). Stability analysis of earth dam by geo-studio software. Int. J. civ. Eng. Technol, 3(2), 437-446. 